УДК $595.768(470.4 / 5)$

DOI 10.18413/2658-3453-2019-1-4-179-192

\title{
ХАРАКТЕРИСТИКА ФАУНЫ И КОМПЛЕКСОВ ЖУКОВ-ФИТОФАГОВ (COLEOPTERA: CHRYSOMELOIDEA, CURCULIONOIDEA) ШИХAНA КУШTAУ (ИШИМБАЙСКИЙ РАЙОН РЕСПУБЛИКИ БАШКОРТОСТАН)
}

\author{
CHARACTERISTICS OF THE FAUNA AND COMPLEXES OF PHYTOPHAGOUS \\ BEETLES (COLEOPTERA: CHRYSOMELOIDEA, CURCULIONOIDEA) OF SHIHAN \\ KUSHTAU (ISHIMBAY DISTRICT OF THE REPUBLIC OF BASHKORTOSTAN)
}

\author{
С.В. Дедюхин \\ S.V. Dedyukhin \\ Удмуртский государственный университет, \\ Россия, 426034, Ижевск, ул. Университетская, 1/1 \\ Udmurt State University, \\ 1/1Universitetskaya St, Izhevsk, 426034, Russia \\ E-mail: ded@udsu.ru
}

\begin{abstract}
Аннотация
В статье приведены сведения о видовом составе и дана общая характеристика фауны жуковфитофагов надсемейств Chrysomeloidea и Curculionoidea шихана Куштау. Это один из трех Стерлитамакских шиханов - уникальных природных объектов Республики Башкортостан, представляющих собой известняковые палеорифы. Установлено очень высокое видовое разнообразие листоедообразных и долгоносикообразных жуков на Куштау (282 вида из 9 семейств - $23.5 \%$ от всей фауны этих групп лесостепной зоны Поволжья и Предуралья). Оригинальность фауны Куштау подчеркивается невысокими коэффициентами сходства Жаккара с фаунами шиханов Юрактау (0.63) и Тратау (0.58). При этом 30 видов жуков, зарегистрированных на Куштау, не известны на других шиханах. Среди биотопических комплексов жуков-фитофагов особенно богаты комплексы растительноядных жуков степных биотопов, в которых сконцентрировано 70 \% видового состава фауны Куштау (197 видов). В степях же (особенно петрофитных) сконцентрировано наибольшее число реликтовых видов. В лесах Куштау зарегистрировано 73 вида жуков-фитофагов (25.6 \% фауны), высокую долю в которых составляют неморальные виды, на восточных границах ареалов. Данные, представленные в статье, подчеркивают уникальность этого природного объекта и необходимость его сохранения.
\end{abstract}

\section{Abstract}

The article provides information on the species composition and gives a general description of the fauna of phytophagous beetles of the superfamilies Chrysomeloidea and Curculionoidea shikhan Kushtau. This is one of the three Sterlitamak shikhans - unique natural sites of the Republic of Bashkortostan, representing limestone paleorifs. A very high species diversity of Chrysomeloidea and Curculionoidea was established in Kushtau (282 species from 9 families, which is $23.5 \%$ of the entire fauna of these groups in the forest-steppe zone of the Volga and Ural regions). The originality of the Kushtau fauna is emphasized by the low Jaccard similarity coefficient with the fauna of other shikhans - Yuraktau (0.63) and Tratau (0.58). Moreover, 30 species of beetles registered in Kushtau are not known on other shikhans. Among the biotopic complexes of phytophagous beetles, despite the relatively small areas of open habitats in Kushtau, the vast majority of species are concentrated in grassy and shrub biotopes. Especially rich are the complexes of herbivorous beetles of the steppe biotopes, in which $70 \%$ of the species composition of the Kushtau fauna is concentrated (197 species). In the steppes (especially petrophytic), the largest number of relict species is concentrated. In the forests of Kushtau, 73 species of phytophagous beetles ( $25.6 \%$ of fauna) were recorded, with a high proportion of non-moral species, on the eastern borders of their ranges. The data presented in the article, emphasizing the uniqueness of this natural object and the need for its conservation. 
Ключевые слова: жуки-фитофаги, Chrysomeloidea, Curculionoidea, шихан Куштау, Республика Башкортостан, фауна, комплексы.

Keywords: phytophagous beetles, Chrysomeloidea, Curculionoidea, Shikhan Kushtau, Republic of Bashkortostan, fauna, complexes.

\section{Введение}

Шихан Куштау - один из трех сохранившихся Стерлитамакских шиханов, уникальных природных объектов Башкирии, представляющих собой конусовидные горыостанцы из органогенного известняка рифового происхождения, расположенных на юге лесостепной зоны Предуралья.

Куштау - самый обширный по площади и наиболее облесенный шихан, имеет форму двугорбого хребта (рис. 1 и 2). Его протяженность с севера на юг 4 км, с запада на восток - 1-1.4 км. Со стороны западного и южного склонов его огибает р. Белая. Координаты южной вершины Куштау $-53.69^{\circ}$ с. ш., $56.08^{\circ}$ в. д.

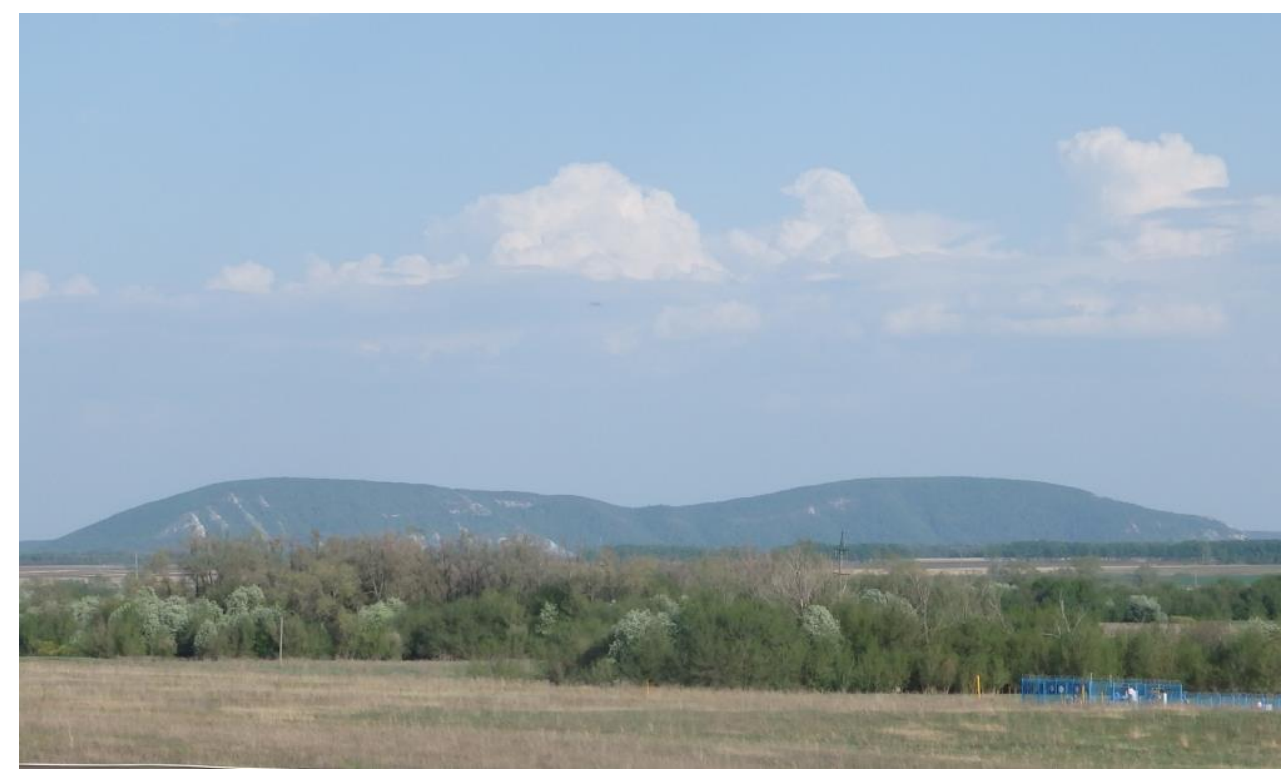

Рис. 1. Шихан Куштау (общий вид с западной стороны)

Fig. 1. Shikhan Kushtau (general view from the western side)

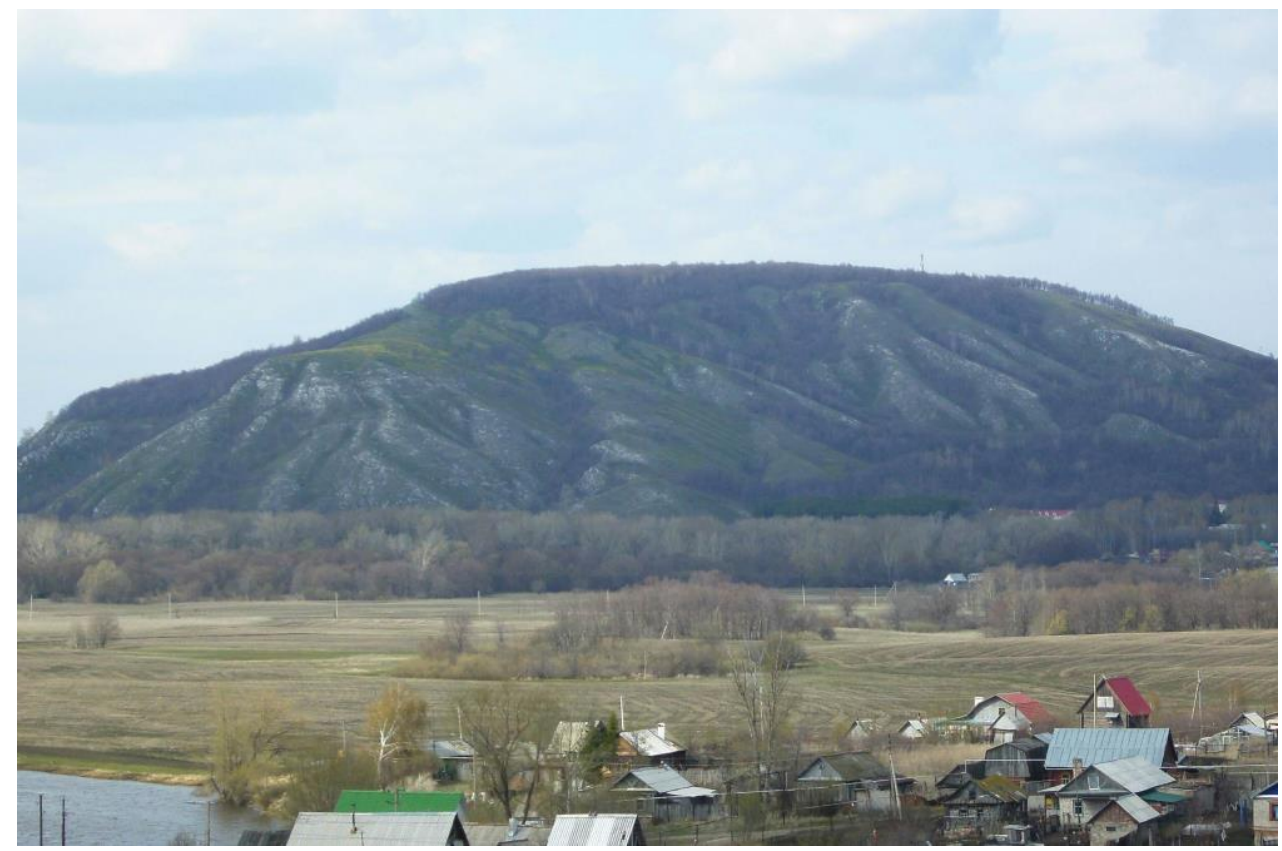

Рис. 2. Шихан Куштау (вид на южную вершину)

Fig. 2. Shikhan Kushtau (view of the southern peak) 
Стерлитамакские шиханы относятся к числу наиболее важных природных объектов на Южном Урале, отличаясь уникальным геологическим составом ископаемой фауны и богатейшим современным биоразнообразием, представляют собой места высокой концентрации редких и нуждающихся в охране видов, а также реликтов и эндемиков уральской флоры [Уникальные ..., 2014].

На Куштау, в отличие от других шиханов, преобладающие площади заняты широколиственными лесами, но в виде довольно крупных пятен (особенно на гребнях южной и восточной экспозиций) здесь присутствуют и разные варианты степей, в том числе и петрофитные. В ложбинах обычны кустарниковые степи. На склонах северных и восточных румбов значительные площади занимают смешанные широколиственные леса и высокотравье на их опушках [Уникальные ..., 2014; Мулдашев, Мартыненко, 2014; Реестр ..., 2016] (рис. 3-5).

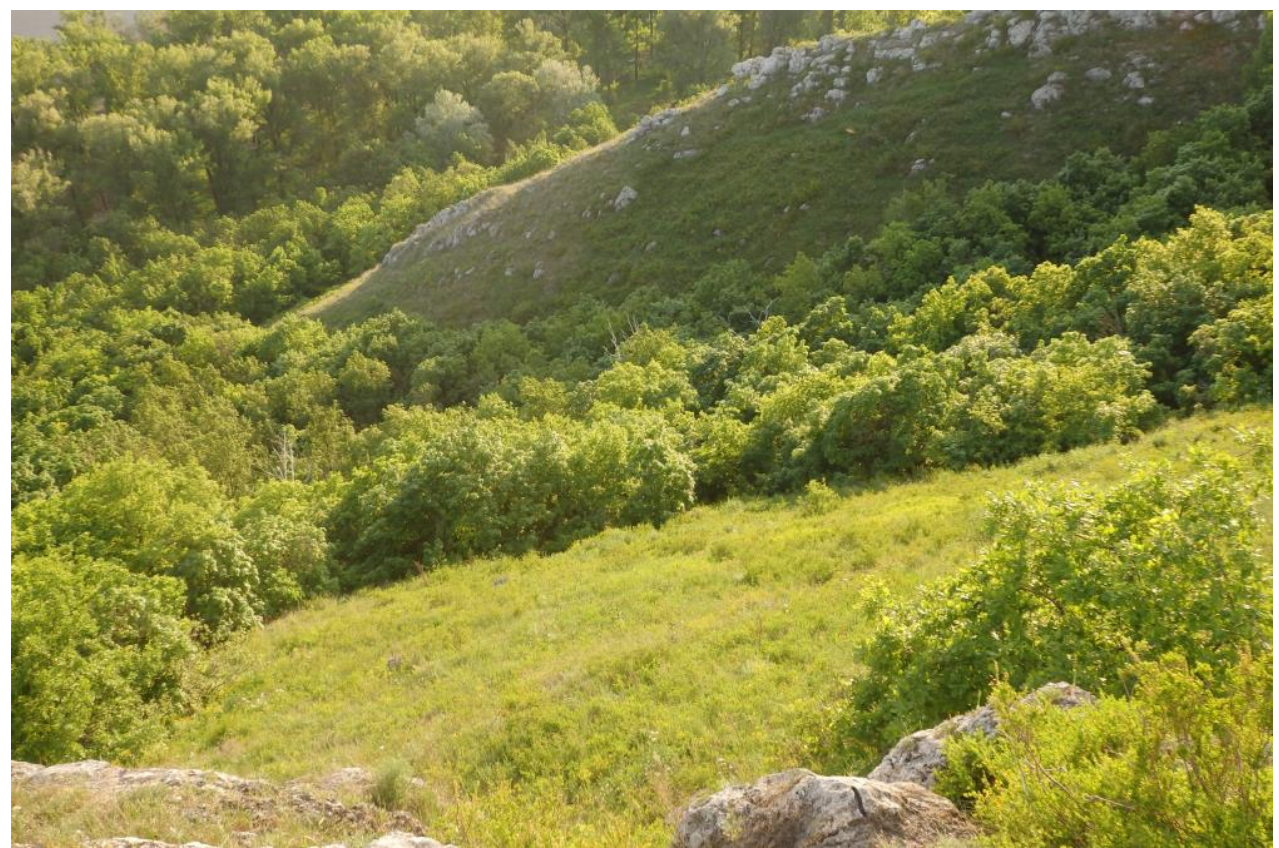

Рис. 3. Каменистые гребни и облесенные ложбины на западном склоне Куштау

Fig. 3. Rocky ridges and forested hollows on the western slope of Kushtau

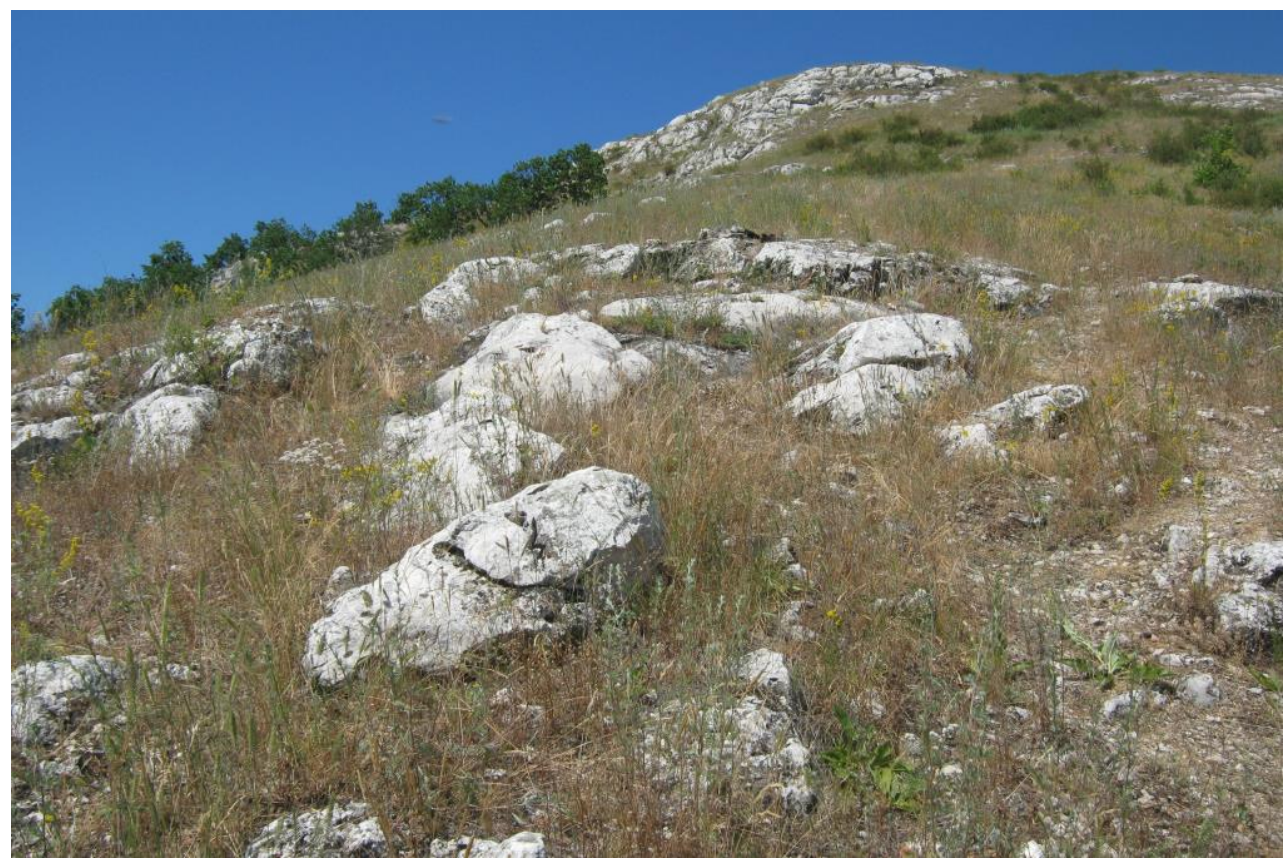

Рис. 4. Петрофитные степи южного склона Куштау

Fig. 4. Stony steppes of the southern slope of Kushtau 


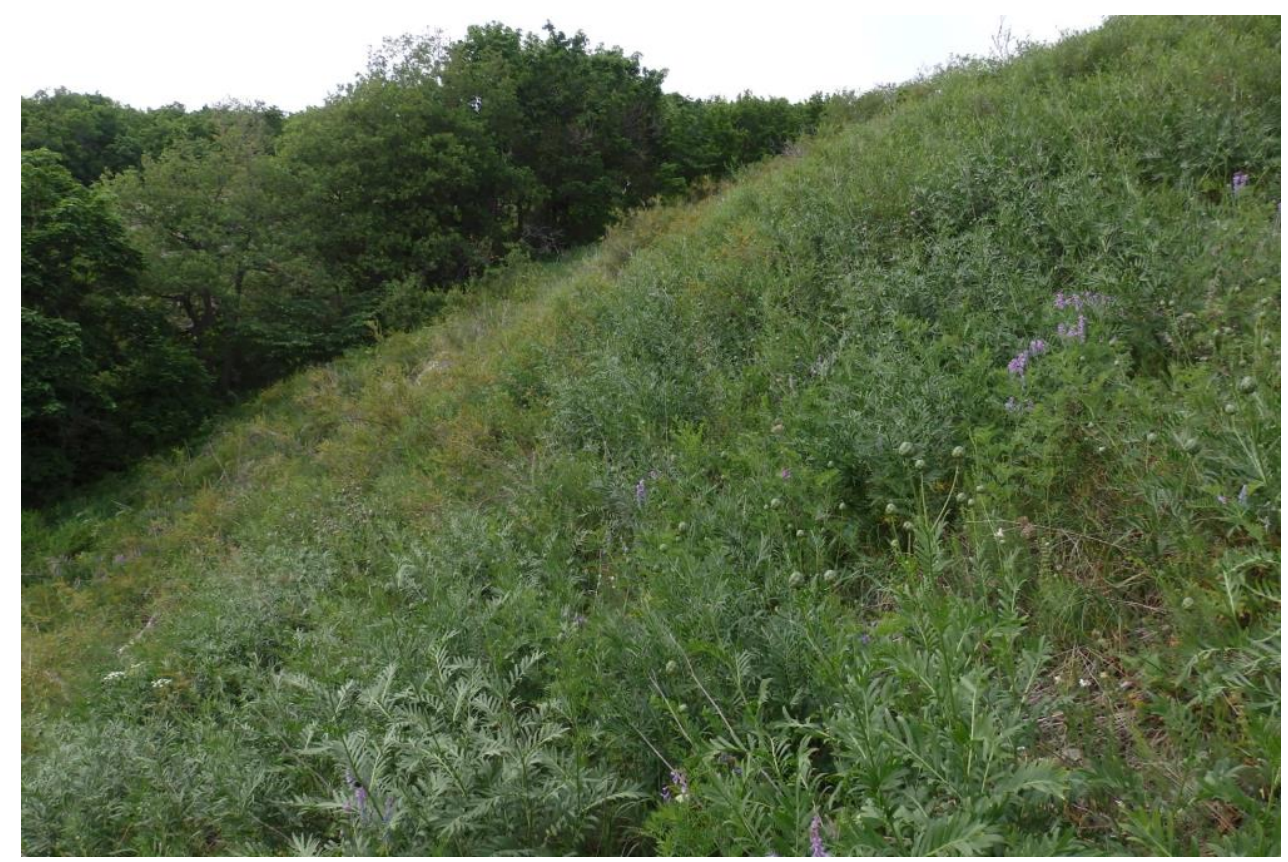

Рис. 5. Заросли василька русского (Centaurea ruthenica Lam.) на юго-восточном склоне Куштау Fig. 5. Bed of Centaurea ruthenica Lam. on the southeastern slope of Kushtau

Шиханы Тратау и Юрактау являются памятниками природы республиканского значения [Уникальные ..., 2014; Реестр ..., 2016] и включены в качестве ключевых объектов в проектируемый в настоящее время геопарк ЮНЕСКО «Торатау» [Создание геопарка..., 2018]. Однако шихан Куштау, несмотря на то, что составляет единый комплекс с другими шиханами, не вошел не только в состав геопарка, но и в принципе не имеет особо охраняемого статуса. Это обусловлено тем, что в его средней части функционирует горнолыжная трасса республиканского значения, а в его основании со времен СССР расположены базы отдыха. Если ограниченное использование шихана под рекреационные нужды не приносит катастрофических последствий для природных комплексов шихана (хотя повышает число рудеральных видов в сообществах), то планы по его промышленной разработке в ближайшие годы для нужд содового производства ставят на грань полного уничтожения этот природный объект. Подчеркнем, также, что самый высокий шихан Шахтау, на котором присутствовали уникальные природные комплексы, в том числе и отсутствующие на оставшихся шиханах [Уникальные ..., 2014], уже полностью разработан.

Специальные исследования листоедов и долгоносиков на Стерлитамакских шиханах проводятся автором статьи в течение 10 лет. В ряде работ [Дедюхин, 2010, 2011a, 2013, 2014, 2015a, 6, 2016б, в, г, 2018; Yunakov et al., 2012] отмечается чрезвычайно высокий уровень видового богатства и своеобразия комплексов жуков-фитофагов шиханов, а также то, что эти локальные природные объекты выступают важнейшими местами концентрации в Предуралье редких и реликтовых видов жуков разного происхождения. Между тем, статей, в которых бы упор был сделан на характеристику и многостороннюю оценку уровня своеобразия фаун отдельных шиханов, пока опубликовано не было.

Цель данной статьи - впервые, на основе последних данных, подробно охарактеризовать фауну растительноядных жуков Куштау и оценить степень ее своеобразия.

\section{Материал и методы исследований}

В основу статьи положены данные по жукам-фитофагам, полученные в результате ряда экспедиционных выездов на Стерлитамакские шиханы, из них на Куштау сборы 
осуществлялись 3-4 мая 2009 г., 18-19 июня 2013 г., 19-20 мая и 19 июня 2016 г., 11-12 мая, 3-4 июня и 6-7 августа 2019 г. В целом фауны листоедов и долгоносиков всех трех шиханов в настоящее время выявлены сравнительно равномерно и довольно подробно.

При полевых изысканиях был использован комплекс методов экологофаунистических исследований насекомых-фитофагов [Арнольди, 1960; Палий, 1970; Медведев, Рогинская, 1988; Беньковский, 2011; Дедюхин, 2011б]. Помимо широко применяемого энтомологического кошения (в том числе в сумерках и ночью) в разных типах растительных ассоциаций, особое внимание уделялось изучению трофических связей с растениями. Последнее проводилось с применением комплекса методов изучения насекомых-фитофагов, основными из которых были сборы жуков с кормовых растений (путем стряхивания жуков в сачок с растений определенного вида, ручного сбора с поверхности растений, окашивания крон деревьев и кустарников, раскопок в основании растений), регистрация фактов питания имаго и личинок, а также сборы частей растений (корни, стебли, плоды), содержащих личинок или куколок, с последующим выведением жуков в лабораторных условиях. В необходимых случаях для уточнения и проверки трофических связей видов ставились лабораторные эксперименты в садках.

Сборы проводились вдоль всего ландшафтного профиля шихана и на склонах различной экспозиции. При этом на Куштау исследована в основном его южная вершина, где присутствуют наиболее разнообразные биотопы (от гиперпетрофитных степей до теневых широколиственных лесов), но в 2019 г. интересные материалы удалось получить и в его северной части.

Всего на Куштау собрано и обработано около 2 тыс. экземпляров жуков.

При определении видов жуков использован набор классических и современных определителей и ревизий [Определитель..., 1965; Dieckmann, 1972, 1974, 1977, 1983, 1988; Коротяев, 1980; Беньковский, 1999; Warchałowski, 2003; Bieńkowski, 2004; Исаев, 2007; Лопатин, 2010] и фондовая коллекция Зоологического института РАН. Большую помощь в окончательной идентификации видов в течение многих лет оказывали Б.А. Коротяев (Зоологический институт РАН) и А.О. Беньковский (Институт проблем Институт проблем экологии и эволюции им. А.Н. Северцова РАН).

\section{Результаты и их обсуждение}

Видовое богатство и своеобразие фауны жуков-фитофагов Куштау. Всего к данному моменту на Куштау удалось зарегистрировать 282 вида жуков-фитофагов из 9 семейств (66 \% от известного состава фауны всех трех шиханов - 427 видов). Учитывая то, что фауна этих групп лесостепной зоны востока Русской равнины (от Приволжья до Предуралья) включает около 1200 видов [Дедюхин, 2016а], то на Куштау зарегистрировано практически четверть видов (23.5\%) растительноядных жуков, обитающих в этом обширном природном регионе. При этом по видовому богатству, Куштау не уступает, и даже несколько превосходит фауну Юрактау (274 вида).

Подавляющее большинство видов $(87.9 \%)$ изученной фауны приходится на 3 семейства: Curculionidae - 117 видов (41.5\% фауны), Chrysomelidae - 102 вида (36.2\%) и Apionidae - 29 видов (10.3\%). Немногими видами представлены семейства Bruchidae 9 видов, Attelabidae (incl. Rhynchtidae) - 7 видов, Anthribidae (incl. Bruchelidae) - 4 вида, Nemonychidae - 1 вид. Кроме того, в составе анализируемой фауны рассматриваются 12 хортофильных и тамнофильных видов усачей (Cerambycidae) и 1 вид травоядных короедов (Thamnurgus petzi Reitter, 1901) (Scolytidae) ${ }^{1}$ (см. таблицу).

1 Cистемь надсемейств Chrysomeloidea и Curculionoidea в течение последних десятилетий неоднократно пересматривались и не могут считаться устоявиимися, поэтому зерновки и короедь в данной статье (как и в предыдущих работах автора) рассматриваются традиционо в ранге отдельных семейств (Bruchidae и Scolytidae), а не в качестве подсемейства Bruchinae (Chrysomelidae) и подсемейства Scolytinae (Curculionidae), как нередко принимается в настоящее время. 
Таблица

Table

Таксономический состав и видовое богатство растительноядных жуков на шихане Куштау (в сравнении с фауной трех Стерлитамакских шиханов в целом)

The taxonomic composition and species richness of phytophagous beetles on the Shikhan Kushtau (in comparison with the fauna of the three Sterlitamak shikhans as a whole)

\begin{tabular}{|c|c|c|c|c|}
\hline \multirow{2}{*}{$\begin{array}{l}\text { Надсемейство } \\
\text { и семейство }\end{array}$} & \multicolumn{2}{|c|}{ Куштау } & \multicolumn{2}{|c|}{$\begin{array}{c}\text { На трех Стерлитамакских } \\
\text { шиханах }\end{array}$} \\
\hline & Число видов & Доля в фауне ( \%) & Число видов & Доля в фауне ( \%) \\
\hline CHRYSOMELOIDEA & 123 & 43.6 & 180 & 42.2 \\
\hline \begin{tabular}{|l|} 
Cerambycidae (только \\
хортобионты)
\end{tabular} & 12 & 4.2 & 12 & 2.8 \\
\hline Chrysomelidae & 102 & 36.2 & 157 & 36.8 \\
\hline Bruchidae & 9 & 3.1 & 11 & 2.6 \\
\hline CURCULIONOIDEA & 159 & 56.4 & 247 & 57.7 \\
\hline Nemonychidae & 1 & 0.3 & 1 & 0.2 \\
\hline $\begin{array}{l}\text { Anthribidae (включая } \\
\text { Bruchelinae) }\end{array}$ & 4 & 1.4 & 4 & 0.9 \\
\hline $\begin{array}{l}\text { Attelabidae (включая } \\
\text { Rhynchitinae) }\end{array}$ & 7 & 2.5 & 9 & 2.1 \\
\hline Apionidae & 29 & 10.3 & 47 & 11.0 \\
\hline Curculionidae & 117 & 41.5 & 184 & 43.1 \\
\hline \begin{tabular}{|l|}
$\begin{array}{l}\text { Scolytidae (только } \\
\text { хортобионты) }\end{array}$ \\
\end{tabular} & 1 & 0.4 & 2 & 0.4 \\
\hline Всего видов & 282 & 100 & 427 & 100 \\
\hline
\end{tabular}

Оригинальность фауны Куштау подчеркивается тем, что из 282 видов, лишь 227 отмечены на Тратау (340 видов) (коэффициент сходства Жаккара двух фаун - 0.58) и 215 на Юрактау (274 вида) (коэффициент Жаккара - 0.63). При этом 30 видов жуков, зарегистрированных на Куштау, не известны на других шиханах. В частности, это Cortodera villosa Heyden, 1876, Theophilea subcylindricollis Hladil, 1988, Agapanthia intermedia Ganglbauer, 1883 (Cerambycidae), Longitarsus lewisii (Baly, 1874), L. monticola Kutschera, 1863, Cassida elongata Weise, 1893 (Chrysomelidae), Bruchidius mordelloides (Baudi, 1886) (Bruchidae), Nemonyx lepturoides (Fabricius, 1801) (Nemonychidae), Neocoenorrhinus minutus (Herbst, 1797) (Attelabidae), Melanobaris hochhuthi (Faust, 1888), Ceutorhynchus sulcatus C. Brisout, 1869, Mecinus ianthinus Germar, 1821, Polydrusus pterygomalis Boheman, 1840 (Curculionidae). Несмотря на то, что фауны шиханов пока установлены не окончательно (но с высокой степенью полноты), эти данные однозначно говорят о значительном своеобразии локальных фаун отдельных гор, косвенным подтверждением чего выступает и специфика флористического состава каждого из шиханов, отмечаемая в работах ботаников [Мулдашев, Мартыненко, 2014].

Биотопические комплексы жуков-фитофагов шихана Куштау. Фауна Куштау имеет лесостепной характер, и основу в ней составляют представители двух ландшафтнобиотопических комплексов: степного и широколиственно-лесного. Отличие мозаики сообществ на Куштау (от Тратау и Юрактау) состоит в преобладании на этом шихане лесных и опушечных группировок, что обусловлено как его преимущественно меридиональной протяженностью, так и непосредственным контактом с р. Белой и прилегающим с северо-востока обширным лесным массивом. В результате, в фауне повышена доля мезофильных лугово-степных, луговых и лесных видов, с другой стороны, наличие каменистых известняковых обнажений и осыпей обусловливает присутствие здесь и реликтового петрофитностепного комплекса видов. 
Несмотря на сравнительно небольшие площади открытых местообитаний, подавляющее большинство видов жуков-фитофагов на Куштау (как и на других шиханах) сосредоточено в травянистых и кустарниковых биотопах. В общей сложности в степях, на лугах, в рудеральных местообитаниях отмечено 246 видов $(87.5 \%)$. Особенно богаты комплексы растительноядных жуков степных биотопов, в которых сконцентрировано 70 \% состава фауны Куштау (197 видов). В лесах Куштау зарегистрировано 73 вида. При сравнении с фауной трех шиханов в целом обращает на себя внимание несколько большая доля в фауне Куштау видов, характерных для лесных сообществ (26 относительно 24 \%) и гораздо более низкая доля видового богатства степных сообществ (70 относительно $90 \%$ видов), что подчеркивает отличие состава биотических комплексов Куштау от других шиханов.

Ниже вкратце охарактеризуем основные биотопические группировки (с указанием характерных видов).

Для разнотравно-злаковых степей (а также остепненных опушек лесов) характерны Theophilea subcylindricollis Hladil, 1988 и Hispa atra Linnaeus, 1767 (на степных злаках), Cryptocephalus laetus Fabricius, 1792 (на Hieracium virosum Pall. и Pilosella echioides (Lumn.) F. Schultz et Sch. Bip.), C. violaceus Laicharting, 1781, C. virens Suffrian, 1847 (на цветах сложноцветных), C. moraei (Linnaeus, 1758) (на зверобоях), C. pygmaeus Fabricius, 1792, Pachybrachis fimbriolatus (Suffrian, 1848), Aphthona nigriscutis Foudras, 1860 (на молочаях), Longitarsus medvedevi Shapiro, 1956 и Gymnetron melanarium (Germar, 1821) (оба вида на верониках), L. jacobaeae (C.R. Waterhouse, 1858) (на Senecio jacobaea L.), Dibolia rugulosa L. Redtenbacher, 1849 и Longitarsus celticus Leonardi, 1975 (оба вида на Stachys recta L.), Dibolia carpathica Weise, 1893 (на Nepeta pannonica L.), D. cryptocephala (Koch, 1803) (на Thymus marschallianus Willd.), Dibolia metallica Motschulsky, 1845 и Squamapion elongatum (Germar, 1812) (узкие олигофаги шалфеев, обычны на Salvia tesquicola Klokov et Pobed. и S. stepposa Shost.), Ceratapion transsylvanicum (Schilsky, 1906) (на Echinops sphaerocephalus L.), Bruchidius pusillus (Germar, 1824), Hemitrichapion pavidum (Germar, 1817), Sitona languidus Gyllenhal, 1834 и Hypera plantaginis (DeGeer, 1775) (4 предыдущих вида на Securigera varia (L.) Lassen), Bruchela orientalis (Strejcek, 1982), B. concolor (Fåhraeus, 1839), Aspidapion soror (Rey, 1895), A. chalceus (Marsham, 1802), Malvaevora timida (Rossi, 1792) (3 последних вида - монофаги на Lavatera thuringiaca L.), Longitarsus obliteratus (Rosenhauer, 1847) и Squamapion flavimanum (Gyllenhal, 1833) (на Origanum vulgare L.), S. samarense (Faust, 1891) (монофаг на Nepeta pannonica L.), S. lukjanovitshi (Korotyaev, 1988) (на Origanum vulgare L. и Thymus marschallianus Willd., а также в каменистых степях на Thymus talijevii Klok. et Shost.), Thamiocolus virgatus (Gyllenhal, 1837), Th. nubeculosus (Gyllenhal, 1837), Th. sahlbergi (Sahlberg, 1845) (все 3 вида - на Phlomoides tuberosa (L.) Moench), Cionus leonhardi Wingelmüller, 1914 и C. olivieri Rosenschold, 1838 (на Verbascum lychnitis L.), Sibinia tibialis (Gyllenhal, 1836) (на Otites spp.), Centricnemus leucogrammus (Germar, 1824).

На каменистых участках степей присутствует обширная и специфичная группа петрофилов, часто тесно связанных с петрофитными видами растений. Это Cryptocephalus flavicollis Fabricius, 1781, Galeruca jucunda (Faldermann, 1837) (обычный вид на Куштау и редкий на других шиханах полифаг травянистых растений, в частности, личинки развиваются на бурачках - Alyssum spp.), Phyllotreta pallidipennis Reitter, 1891, Ph. erysimi Weise, 1900, Ph. weiseana Jacobson, 1901 (все три перечисленных вида рода в основном также питаются на бурачках), Aphthona franzi (Heikentinger, 1944) (на петрофитных молочаях, в особенности на Euphorbia seguieriana Neck.), Psylliodes isatidis Heikertinger, 1913 и Ceutorhynchus kaszabi Korotyaev, 1980 (на Isatis costata C.A. Mey), Aizobius sedi (Germar, 1818) (на Hylotelephium stepposum (Boriss.) Tzvel. и Hylotelephium triphyllum (Haw.) Holub), Longitarsus ganglbaueri Heikertinger, 1912 (на крестовниках - Senecio spp.), Bruchidius unicolor (Olivier, 1795), B. mordelloides (Baudi, 1886), Larinus vulpes (Olivier, 
1807) (последний вид обитает в разных типах степей на мордовниках - Echinops ruthenicus Bieb. и E. sphaerocephalus L.), Larinus iaceae volgensis Becker, 1864 (преимущественный олигофаг наголоваток, на Куштау собран с Jurinea ledebourii Bunge), Melanobaris nigritarsis (Boheman, 1844), Aulacobaris violaceomicans (Solari, 1904) (оба вида развиваются в корнях некоторых петрофитностепных крестоцветных, в том числе на Clausia aprica (Steph.) Korn.-Trotzk. s. 1.), Ceutorhynchus potanini Korotyaev, 1980 (монофаг на Alyssum lenense Adams), Oprohinus jakovlevi (Schultze, 1902) (на луках - Allium spp.), Prisistus caucasicus bohemani Collonnelli, 1986 (кормовые растения не известны), Tychius longulus Desbrochers, 1873 (олигофаг некоторых астрагалов, на Куштау живет на реликтовом виде Astragalus helmii Fisch.), Sibinia phalerata (Gyllenhal, 1836), S. unicolor (Fåhraeus, 1843) (последний вид узкий олигофаг качимов, на Куштау связан с Gypsophila altissima L.), Trachyphloeus spinimanus Germar, 1824, Cycloderes pilosulus (Herbst, 1796). Для тимьянов каменистых степей и скал (Thymus talijevii Klok. et Shost. и Th. cimicinus Blum ex Ledeb.) специфичен Squamapion oblivium (Schilsky, 1902). Помимо специфических видов в петрофитных степях могут встречаться и некоторые представители, перечисленные в группе комплекса разнотравно-ковыльных степей.

Интересно, что некоторые виды, отмеченные на Куштау, связаны с растениями пока не отмеченными на этом шихане ботаниками. Так только на Куштау в каменистой степи выкошен Nemonyx lepturoides (Fabricius, 1801), единственный известный на шиханах вид реликтового семейства Nemonychidae, считающийся монофагом на живокости полевой - Consolida regalis Gray. На осыпях на дымянке Шлейхера (Fumaria schleicheri Soy.-Willem.) собран Sirocalodes depressicollis (Gyllenhal, 1813) - узкий олигофаг дымянок, ранее указываемый только для Fumaria officinalis L. [Dieckmann, 1972; Дедюхин, 2012].

Часть видов на Куштау связана в основном с рудеральной растительностью, обильно произрастающей (наравне с некоторыми петрофитами) на антропогенно нарушенных участках склонов. В частности, это Chaetocnema breviuscula (Faldermann, 1837), Phyllotreta vittula (L. Redtenbacher, 1849), Psylliodes tricolor Weise, 1888, Omphalapion hookerorum (Kirby, 1808), Ceutorhynchus sulcatus C. Brisout, 1869, Pseudostyphlus pillumus (Gyllenhal, 1835) и др.

Своеобразные группировки складываются в высокотравье распадков и ложбин. В частности, в зарослях василька русского (Centaurea ruthenica Lam.) (см. рис. 5) отмечена группа региональных монофагов этого вида. Это усач Cortodera villosa Heyden, 1876 и долгоносик Pseudocleonus dauricus Gebler, 1830 (оба вида развиваются в корнях), а также листоед Cassida elongata Weise, 1893 (из них первый и третий вид на шиханах известны только на Куштау, а Pseudocleonus dauricus еще и на Тратау). Очень показательно, что этот, явно реликтовый комплекс, представлен формами разного генезиса и, следовательно, времени их широкого распространения. Если Cortodera villosa евро-кавказский вид, представленный на Южном Урале подвидом C. v. mikhailovi Danilevsky, 2001, то Cassida elongata причерноморско-казахстанский южностепной вид, а Pseudocleonus dauricus центральноазиатско-южносибирский вид (в Южной Сибири и горах Средней Азии живет на других сложноцветных).

Последний вид на Урале и востоке Русской равнины очень редок, имея здесь узколокальное островное распространение реликтового типа на древних останцах, а в Башкирии известен только на шиханах. C учетом реальной угрозы уничтожения популяции на Куштау, он требует принятия особых мер охраны на региональном уровне и включения в новую редакцию Красной книги Республики Башкортостан как индикатор реликтовых горностепных сообществ.

Другим характерным видом высокотравных сообществ Куштау выступает живокость сетчатоплодная (Delphinium dictyocarpum DC.). В стеблях этого растения на шиханах развивается редкий европейский вид травоядного короеда Thamnurgus petzi Reitter, 1901. 
Богато на Куштау представлен комплекс кустарниковых и петрофитнокустарниковых степей, специфика которого определяется в первую очередь фитофагами степных кустарников: Cryptocephalus laevicollis Gebler, 1830, C. schaefferi Schrenk, 1789, Temnocerus subglaber (Desbrochers, 1897) (все перечисленные виды связаны в основном или исключительно с Spiraea crenata L. и S. hypericifolia L.), Cryptocephalus elongatus Germar, 1824, Kytorhinus quadriplagiatus Motschulsky, 1839, Tychius uralensis Pic, 1902 (все 3 вида - монофаги на Caragana frutex (L.) C. Koch), Pachybrachis tessellatus (Olivier, 1791) (на Rhamnus cathartica L.), Neocoenorhinidius pauxillus (Germar, 1824) и Rhynchites auratus (Scopoli, 1763) (в основном на Amygdalus nana L. и Cerasus fruticosa Pall.), Otiorhynchus chrysostictus Gyllenhal, 1834, O. concinnus Gyllenhal, 1834 (полифаги кустарников и степного высокотравья).

В лесах Куштау зарегистрировано 73 вида жуков-фитофагов (25.6\%), причем многие из них встречаются в зарослях степных кустарников либо проникают под полог лесов из прилегающих степных и луговых биоценозов. Значительная часть из отмеченных в лесах видов - типичные неморальные формы, находящиеся здесь вблизи восточных границ своих ареалов. Так, на Куштау обнаружена почти вся группировка монофагов дуба (Attelabus nitens (Scop.), Curculio venosus (Grav.), C. glandium Marsh., Archarius pyrrhoceras (Marsh.), Orchestes hortorum (F.), Altica quercetorum Foudr.), известных на Урале. На вязах (Ulmus spp.) обитают Galerucella luteola (Müller, 1766) и Luperus xanthopoda (Schrank, $1781)^{2}$.

Под пологом лесов на розоцветных (Rubus caesius L., R. idaeus L., R. saxatilis L.) обычны Batophila rubi (Paykull, 1799) и B. fallax Weise, 1888, на жимолости татарской (Lonicera tatarica L.) - Rhynchaenus xylostei Clairville, 1798. Калину (Viburnum opulus L.) повреждает Pyrrhalta viburni (Paykull, 1799). На травянистых растениях в лесах зарегистрированы Lixus iridis Olivier, 1807 (на Aegopodium podograria L. и Heracleum sibiricum L.), Mogulones pallidicornis (Gougelet \& Brisout de Barneville, 1860) (на Pulmonaria obscura Dumort. и P. mollis Wulf. ex Hornem.), Chrysolina fastuosa (Scopoli, 1763) и Coeliastes lamii (Fabricius, 1792) (на Lamium album L.), Cionus tuberculosus (Scopoli, 1763) (на Scrophularia nodosa L.). С чистецом лесным (Stachys sylvatica L.) связаны его преимущественный монофаг Datonychus urticae (Boheman, 1845) (неморальный вид в Башкирии, зарегистрирован только в лесном массиве в северной части Куштау) и широкий олигофаг губоцветных Cassida viridis Linnaeus, 1758. На уральском эндемике чине Литвинова (Lathyrus litvinovii Iljin) обычна зерновка Bruchus affinis Froelich, 1799, широкий олигофаг бобовых.

\section{Заключение}

Таким образом, можно констатировать, что на Куштау представлены богатые и своеобразные комплексы растительноядных жуков, включающие редкие и реликтовые виды, многие из которых связаны с произрастающими здесь редкими и особо охраняемыми видами растений. Представленные данные однозначно свидетельствуют о перспективности дальнейшего углубленного изучения растительноядных жуков Куштау (как и других групп насекомых), тем более, что, наравне с двумя другими шиханами, он может служить эталонным объектом для изучения реликтовых сообществ Предуралья и закономерностей «островного эффекта». Поэтому представляется чрезвычайно важным сохранение всех трех уникальных гор и введение запрета на планируемую в ближайшие годы промышленную разработку шихана Куштау с приданием ему природоохранного статуса.

${ }^{2}$ Своеобразие неморального энтомокомплекса Куштау подчеркивается находкой двух видов жуков из других групп, включенных в Красную книгу РФ: реликтового усача - альпийской розалии (Rosalia alpina (Linnaeus, 1758)), развивающегося в основном на клене (Acer plantanoides L.), и гладкой бронзовки (Protaеtia speciosissima (Scopoli, 1786) (=Netocia aeruginosa Drury, 1770)) (Scarabaeidae), связанной со старыми дуплистыми дубами. При этом, насколько нам известно, последний вид впервые обнаружен в Башкирии. 


\section{Благодарности}

Автор глубоко благодарен А.О. Беньковскому (Институт проблем экологии и эволюиии РАН, г. Москва) и Б.А. Коротяеву (Зоологический институт РАН, г. СанктПетербург) за помощь в определении видов жуков, а также В.Б. Мартыненко и А.А. Мулдашеву (Уфимский Институт биологии УФИЦ РАН, г. Уфа) за помощь в определении видов растений.

\section{Список литературы}

1. Арнольди Л.В. 1960. Краткие методические указания по изучению консортивных связей насекомых при биокомплексных исследованиях. $B$ кн.: Программно-методическая записка по биокомплексному и геоботаническому изучению степей и пустынь Центрального Казахстана. М.; Л., АН СССР: 9-14.

2. Беньковский А.О. 1999. Определитель жуков-листоедов (Coleoptera, Chrysomelidae) европейской части России и европейских стран ближнего зарубежья. М., Техполиграфцентр, 204 с.

3. Беньковский А.О. 2011. Жуки-листоеды европейской части России (по материалам докторской диссертации). М., Lambert Academic Publishing, 535 c. (in Russian)

4. Дедюхин С.В. 2010. Ранневесенний аспект фауны жесткокрылых-фитофагов (Coleoptera: Chrysomeloidea, Curculionoidea) известняковых рифовых шиханов близ г. Стерлитамак. $B$ кн.: Проблемы и перспективы изучения естественных и антропогенных экосистем Урала и прилегающих регионов. Материалы Всероссийской конференции. Стерлитамак, Стерлитамакская государственной педагогической академия им. Зайнаб Биишевой: 63-68.

5. Дедюхин С.В. 2011а. Материалы по интересным находкам жуков-долгоносиков (Coleoptera, Curculionoidea) на востоке Русской равнины. Вестник Удмуртского университета. Серия Биология. Науки о Земле, (2): 90-104.

6. Дедюхин С.В. 2011б. Принципы и методы эколого-фаунистических исследований наземных насекомых: учебно-методическое пособие. Ижевск, Удмуртский университет, 93 с.

7. Дедюхин С.В. 2012. Долгоносикообразные жесткокрылые (Coleoptera, Curculionoidea) Вятско-Камского междуречья: фауна, распространение, экология. Ижевск, Удмуртский университет, 340 с. (in Russian)

8. Дедюхин С.В. 2013. Особенности комплексов жуков-фитофагов (Coleoptera: Chrysomeloidea, Curculionoidea) каменистых склонов лесостепи Заволжья и Предуралья. $B$ кн.: Лесостепь Восточной Европы: структура, динамика, охрана. Сборник статей Международной научной конференции. Пенза, Изд-во Пензенского государственного университета: 289-291.

9. Дедюхин С.В. 2014. К фауне и экологии жуков-фитофагов (Coleoptera: Chrysomeloidea, Curculionoidea) Заволжья и Предуралья. Энтомологическое обозрение, 93 (3): 568-593.

10. Дедюхин C.В. 2015a. Разнообразие жуков-фитофагов (Coleoptera: Chrysomeloidea, Curculionoidea) в степных резерватах Высокого Заволжья и Предуралья. $B$ кн.: Степи Северной Евразии. Материалы VII Международного симпозиума. Оренбург, ИС УрО РАН, Печатный дом «Димур»: 291-293.

11. Дедюхин С.В. 2015б. Разнообразие растительноядных жуков (Coleoptera: Chrysomeloidea, Curculionoidea) в степных сообществах лесостепи Высокого Заволжья. Энтомологическое обозрение, 94 (3): 626-650.

12. Дедюхин С.В. 2016а. Зональная дифференциация фауны растительноядных жуков (Coleoptera: Chrysomeloidea, Curculionoidea) на востоке Русской равнины. Евразиатский энтомологический журнал, 15 (2): 164-182.

13. Дедюхин С.В. 2016б. Видовое богатство и зональные особенности парциальных фаун жуков-фитофагов (Coleoptera, Chrysomeloidea, Curculionoidea) травянистых склонов на востоке Русской равнины и в Предуралье. Зоологический журнал, 95 (9): 1053-1065.

14. Дедюхин С.В. 2016в. Реликтовые элементы фауны жуков-фитофагов (Coleoptera: Chrysomeloidea, Curculionoidea) востока Русской равнины и их природные резерваты. Вестник Пермского университета. Серия Биология. (2): 124-143.

15. Дедюхин С.В. 2016г. Новые данные о составе растительноядных жуков (Coleoptera: Attelabidae, Chrysomelidae, Curculionidae), связанных с дубом (Quercus robur L.), в Предуралье и на Южном Урале. В кн.: Природа, наука и туризм. Сборник материалов всероссийской научно- 
практической конференции, посвященной 30-летию национального парка «Башкирия». Уфа, Гилем, Башкирская энциклопедия: 145-152.

16. Дедюхин С.В. 2018. Стерлитамакские шиханы - уникальные резерваты видового богатства и реликтовых элементов фауны растительноядных жуков (Coleoptera: Chrysomeloidea, Curculionoidea) Лесостепного Предуралья. $B$ кн.: Материалы XVI Всероссийской научно-практ. конференции «Зыряновские чтения». Курган, Изд-во Курганского государственного университета: $255-256$.

17. Исаев А.Ю. 2007. Определитель жесткокрылых Среднего Поволжья. Ч. 3. PolyphagaPhytophaga. Ульяновск, Вектор-С, $256 \mathrm{c.}$

18. Лопатин И.К. 2010. Жуки-листоеды (Insecta, Coleoptera, Chrysomelidae) Центральной Азии. Минск, Белорусский государственный университет, 511 с.

19. Медведев Л.Н., Рогинская Е.Я. 1988. Каталог кормовых растений листоедов СССР. М., ПЭМ ВНИИИС Госстроя СССР, $192 \mathrm{c}$.

20. Мулдашев А.А., Мартыненко В.Б. 2014. К характеристике флоры и растительности шиханов Тра-тау и Юрак-тау. Известия Уфимского научного иентра PAH, (2): 68-74.

21. Определитель насекомых европейской части СССР. Т. 2. Жесткокрылые и веерокрылые. 1965. Г.Я. Бей-Биенко (ред.). М.; Л., Наука, 668 с.

22. Палий В.Ф. 1970. Методика изучения фауны и фенологии насекомых. Воронеж, Центрально-черноземное книжное изд-во, 190 с.

23. Реестр особо охраняемых природных территорий республиканского значения, 2016. (Изд. 3-е, перераб.). Уфа, Издательство «Белая река», 400 с.

24. Создание геопарка Торатау - этап сохранения Стерлитамакских шиханов. Оренбургское региональное отделение РГО. 2018. URL: https://www.rgo.ru/ru/article/sozdaniegeoparka-toratau-etap-sohraneniya-sterlitamakskih-shihanov (дата обращения 13 декабря 2018).

25. Уникальные памятники природы - шиханы Тратау и Юрактау. 2014. А.И. Мелентьев и В.Б. Мартыненко (ред.). Уфа, Гилем, Башкирская энциклопедия, 312 с.

26. Bieńkowski A.O. 2004. Leaf-beetles (Coleoptera: Chrysomelidae) of the Eastern Europe. New key to subfamilies, genera and species. Moscow, Mikron-print, $278 \mathrm{p}$.

27. Dieckmann L. 1972. Beiträge zur Insektenfauna der DDR: Coleoptera - Curculionidae: Ceutorhynchinae. Beiträge zur Entomologie, 22 (1-2): 3-128.

28. Dieckmann L. 1974. Beiträge zur Insektenfauna der DDR: Coleoptera - Curculionidae (Rhinomacerinae, Rhynchitinae, Attelabinae, Apoderinae). Beiträge zur Entomologie, 24 (1/4): 5-54. (in German)

29. Dieckmann L. 1977. Beiträge zur Insektenfauna der DDR: Coleoptera - Curculionidae: Apioninae. Beiträge zur Entomologie, 27 (1): 7-143. (in German)

30. Dieckmann L. 1983. Beiträge zur Insektenfauna der DDR: Coleoptera - Curculionidae (Tanymecinae, Leptopiinae, Cleoninae, Tanyrhinchinae, Cossoninae, Raymondionyminae, Bagoinae, Tanysphyrinae. Beiträge zur Entomologie, 33 (2). 257-381. (in German)

31. Dieckmann L. 1988. Beiträge zur Insektenfauna der DDR: Coleoptera - Curculionidae (Curculioninae: Ellescini, Aca lyptini, Tychiini, Anthonomini, Curculionini). Beiträge zur Entomologie, 38 (2): 365-468. (in German)

32. Yunakov N.N., Dedyukhin S. V., Filimonov R. V. 2012. Towards the survey of Entiminae weevils (Coleoptera, Curculionidae) of Russia: species occurring in the Volga and Ural Regions. Russian Entomological Journal, 21 (1): 57-72.

33. Wanat M. 1995. Systematics and phylogeny of the tribe Ceratapiini (Coleoptera: Curculionoidea: Apionidae). Warszaw, Biologica Silesiae, 406 p.

34. Warchałowski A. 2003. Chrysomelidae. The leaf-beetles of Europe and the Mediterranean area. Warszaw, Natura optima dux Foundation, 600 p.

\section{Reference}

1. Arnoldi L.V. 1960. Kratkiye metodicheskiye ukazaniya po izucheniyu konsortivnykh svyazey nasekomykh pri biokompleksnykh issledovaniyakh [Brief guidelines for the study of consortion bonds of insects in biocomplex studies]. In: Programmno-metodicheskaya zapiska po biokompleksnomu i geobotanicheskomu izucheniyu stepey i pustyn' Tsentral'nogo Kazakhstana [Program note on biocomplex and geobotanical study of the steppes and deserts of Central Kazakhstan]. Moskow; Leningrad, USSR Academy of Sciences: 9-14. 
2. Ben'kovskiy A.O. 1999. Opredelitel' zhukov-listoyedov (Coleoptera, Chrysomelidaye) evropeyskoy chasti Rossii i evropeyskikh stran blizhnego zarubezh'ya [Key to leaf beetles (Coleoptera, Chrysomelidae) of the European part of Russia and European countries of the near abroad]. Moskow, Tekhpoligraftsentr, $204 \mathrm{p}$.

3. Ben'kovskiy A.O. 2011. Zhuki-listoyedy evropeyskoy chasti Rossii (po materialam doktorskoy dissertatsii) [Leaf beetles of the European part of Russia (based on the materials of the doctoral dissertation)]. Moskow, Lambert Academic Publishing, 535 p.

4. Dedyukhin S.V. 2010. Rannevesenniy aspekt fauny zhestkokrylykh-fitofagov (Coleoptera: Chrysomeloidea, Curculionoidea) izvestnyakovykh rifovykh shikhanov bliz g. Sterlitamak [The early spring aspect of the fauna of Coleoptera phytophages (Coleoptera: Chrysomeloidea, Curculionoidea) of limestone reef shihanas near the town of Sterlitamak]. In: Problemy i perspektivy izucheniya estestvennykh i antropogennykh ekosistem Urala i prilegayushchikh regionov. Materialy Vserossiyskoy konferentsii [Problems and prospects of studying the natural and anthropogenic ecosystems of the Urals and adjacent regions. Materials of the All-Russian Conference]. Sterlitamak, Sterlitamak State Pedagogical Academy named after Zainab Biisheva: 63-68.

5. Dedyukhin S.V. 2011a. Materials on interesting finds of weevils (Coleoptera, Curculionoidea) in the east of the Russian Plain. Bulletin of the Udmurt University. Biology Series. Earth sciences, (2): 90-104. (in Russian)

6. Dedyukhin S.V. 2011b. Printsipy i metody ekologo-faunisticheskikh issledovaniy nazemnykh nasekomykh: uchebno-metodicheskoye posobiye [Principles and methods of ecologic-faunistic studies of terrestrial insects: a training manual]. Izhevsk, Udmurt University, 93 p.

7. Dedyukhin S.V. 2012. Dolgonosikoobraznyye zhestkokrylyye (Coleoptera, Curculionoidea) Vyatsko-Kamskogo mezhdurech'ya: fauna, rasprostraneniye, ekologiya [Weevil-like (Coleoptera, Curculionoidea) of the Vyatka-Kama interfluve: fauna, distribution, ecology]. Izhevsk, Udmurt University, $340 \mathrm{p}$.

8. Dedyukhin S.V. 2013. Osobennosti kompleksov zhukov-fitofagov (Coleoptera: Chrysomeloidea, Curculionoidea) kamenistykh sklonov lesostepi Zavolzh'ya i Predural'ya [Features of phytophagous beetles complexes (Coleoptera: Chrysomeloidea, Curculionoidea) of rocky slopes of the forest-steppe of the Volga and Ural regions]. In: Lesostep' Vostochnoy Yevropy: struktura, dinamika, okhrana. Sbornik statey Mezhdunarodnoy nauchnoy konferentsii [Forest-steppe of Eastern Europe: structure, dynamics, protection. Collection of articles of the International Scientific Conference]. Penza, Publishing House of Penza State University: 289-291. (in Russian)

9. Dedyukhin S.V. 2014. On the fauna and ecology of phytophagous beetles (Coleoptera: Chrysomeloidea, Curculionoidea) of the Volga and Ural regions. Entomological review, 93 (3): 568-593. (in Russian)

10. Dedyukhin S.V. 2015a. Raznoobraziye zhukov-fitofagov (Coleoptera: Chrysomeloidea, Curculionoidea) v stepnykh rezervatakh Vysokogo Zavolzh'ya i Predural'ya [A variety of phytophagous beetles (Coleoptera: Chrysomeloidea, Curculionoidea) in the steppe reserves of the High Volga and Ural regions]. In: Stepi Severnoy Evrazii. Materialy VII Mezhdunarodnogo simpoziuma [Steppes of Northern Eurasia. Materials of the VII International Symposium]. Orenburg, IS Ural Branch of the Russian Academy of Sciences, Dimur Printing House: 291-293.

11. Dedyukhin S.V. 2015b. Variety of phytophagous beetles (Coleoptera: Chrysomeloidea, Curculionoidea) in the steppe communities of the forest-steppe of the High Volga. Entomological review, 94 (3): 626-650. (in Russian)

12. Dedyukhin S.V. 2016a. Zonal differentiation of the fauna of phytophagous beetles (Coleoptera: Chrysomeloidea, Curculionoidea) in the East of the Russian Plain. Eurasian Entomological Journal, 15 (2): 164-182. (in Russian)

13. Dedyukhin S.V. 2016b. The species richness and zonal features of the partial fauna of phytophagous beetles (Coleoptera, Chrysomeloidea, Curculionoidea) of grassy slopes in the east of the Russian Plain and in the Urals. Zoological journal, 95 (9): 1053-1065. (in Russian)

14. Dedyukhin S.V. 2016c. Relict elements of the fauna of phytophagous beetles (Coleoptera: Chrysomeloidea, Curculionoidea) of the East of the Russian Plain and their natural reserves. Bulletin of Perm University. Biology Series, (2): 124-143. (in Russian)

15. Dedyukhin S.V. 2016d. Novyye dannyye o sostave rastitel'noyadnykh zhukov (Coleoptera: Attelabidae, Chrysomelidae, Curculionidae), svyazannykh s dubom (Quercus robur L.), v Predural'ye i na Yuzhnom Urale [New data on the composition of phytophagous beetles (Coleoptera: Attelabidae, 
Chrysomelidae, Curculionidae) associated with oak (Quercus robur L.) in the Urals and the Southern Urals]. In: Priroda, nauka i turizm. Sbornik materialov vserossiyskoy nauchno-prakticheskoy konferentsii, posvyashchennoy 30-letiyu natsional'nogo parka «Bashkiriya» [Nature, Science, and Tourism. Collection of materials of the All-Russian scientific and practical conference dedicated to the 30th anniversary of the Bashkiria National Park]. Ufa, Gilem, Bashkir Encyclopedia: 145-152.

16. Dedyukhin S.V. 2018. Sterlitamakskiye shikhany - unikal'nyye rezervaty vidovogo bogatstva i reliktovykh elementov fauny rastitel'noyadnykh zhukov (Coleoptera: Chrysomeloidea, Curculionoidea) Lesostepnogo Predural'ya [Sterlitamak shihan - unique reserves of species richness and relict elements of the fauna of phytophagous beetles (Coleoptera: Chrysomeloidea, Curculionoidea) of the forest-steppe Cis-Urals areas]. In: Materialy XVI Vserossiyskoy nauchno-prakt. konferentsii «Zyryanovskiye chteniya» [Materials of the XVI All-Russian Scientific and Practical. conferences «Zyryanov readings»]. Kurgan, Publishing house of Kurgan State University: 255-256.

17. Isaev A.Yu. 2007. Opredelitel' zhestkokrylykh Srednego Povolzh'ya. Ch. 3. PolyphagaPhytophaga. [Key to beetles of the Middle Volga. Part 3. Polyphaga - Phytophaga]. Ulyanovsk, Vector$\mathrm{C}, 256 \mathrm{p}$.

18. Lopatin I.K. 2010. ZHuki-listoyedy (Insecta, Coleoptera, Chrysomelidae) Tsentral'noy Azii. [Leaf beetles (Insecta, Coleoptera, Chrysomelidae) of Central Asia]. Minsk, Belarusian State University, $511 \mathrm{p}$.

19. Medvedev L.N., Roginskaya E.Ya. 1988. Katalog kormovykh rasteniy listoyedov SSSR. [Catalog of forage plants of leaf beetles of the USSR]. Moskow, PEM VNIIIS Gosstroy of the USSR, $192 \mathrm{p}$.

20. Muldashev A.A., Martynenko V.B. 2014. On the characteristics of the flora and vegetation of Shihan Tra-tau and Yurak-tau. Izvestia Ufimskogo Nauchnogo Tsentra RAN [Proceedings of the RAS Ufa Scientific Centre], (2): 68-74. (in Russian)

21. Opredelitel' nasekomykh evropeyskoy chasti SSSR. T. 2. Zhestkokrylyye i veyerokrylyye. [Key to insects of the European part of the USSR. T. 2. Rugged and fan-winged]. 1965. G.Ya. BeyBienko (ed.). M.; L., Science, 668 p.

22. Paliy V.F. 1970. Metodika izucheniya fauny i fenologii nasekomykh [Methods of studying the fauna and phenology of insects]. Voronezh, Central Black Soil Book Publishing House, 190 p.

23. Reyestr osobo okhranyayemykh prirodnykh territoriy respublikanskogo znacheniya [Register of Specially Protected Natural Territories of Republican Significance]. 2016. (Ed. 3rd, revised). Ufa, Publishing House «White River», $400 \mathrm{p}$.

24. Sozdaniye geoparka Toratau - etap sokhraneniya Sterlitamakskikh shikhanov. Orenburgskoye regional'noye otdeleniye RGO. 2018. URL: https://www.rgo.ru/ru/article/sozdanie-geoparka-toratauetap-sohraneniya-sterlitamakskih-shihanov (accessed 13 December 2018).

25. Unikal'nyye pamyatniki prirody - shikhany Tratau i YUraktau. [Unique natural monuments are shikhans Tratau and Yuraktau]. 2014. A.I. Melentyev and V.B. Martynenko (eds.). Ufa, Gilem, Bashkir Encyclopedia, 312 p.

26. Bieńkowski A.O. 2004. Leaf-beetles (Coleoptera: Chrysomelidae) of the Eastern Europe. New key to subfamilies, genera and species. Moscow, Mikron-print, $278 \mathrm{p}$.

27. Dieckmann L. 1972. Beiträge zur Insektenfauna der DDR: Coleoptera - Curculionidae: Ceutorhynchinae. Beiträge zur Entomologie, 22 (1-2): 3-128.

28. Dieckmann L. 1974. Beiträge zur Insektenfauna der DDR: Coleoptera - Curculionidae (Rhinomacerinae, Rhynchitinae, Attelabinae, Apoderinae). Beiträge zur Entomologie, 24 (1/4): 5-54. (in German)

29. Dieckmann L. 1977. Beiträge zur Insektenfauna der DDR: Coleoptera - Curculionidae: Apioninae. Beiträge zur Entomologie, 27 (1): 7-143. (in German)

30. Dieckmann L. 1983. Beiträge zur Insektenfauna der DDR: Coleoptera - Curculionidae (Tanymecinae, Leptopiinae, Cleoninae, Tanyrhinchinae, Cossoninae, Raymondionyminae, Bagoinae, Tanysphyrinae. Beiträge zur Entomologie, 33 (2). 257-381. (in German)

31. Dieckmann L. 1988. Beiträge zur Insektenfauna der DDR: Coleoptera - Curculionidae (Curculioninae: Ellescini, Aca lyptini, Tychiini, Anthonomini, Curculionini). Beiträge zur Entomologie, 38 (2): 365-468. (in German)

32. Yunakov N.N., Dedyukhin S. V., Filimonov R. V. 2012. Towards the survey of Entiminae weevils (Coleoptera, Curculionidae) of Russia: species occurring in the Volga and Ural Regions. Russian Entomological Journal, 21 (1): 57-72. 
33. Wanat M. 1995. Systematics and phylogeny of the tribe Ceratapiini (Coleoptera: Curculionoidea: Apionidae). Warszaw, Biologica Silesiae, 406 p.

34. Warchałowski A. 2003. Chrysomelidae. The leaf-beetles of Europe and the Mediterranean area. Warszaw, Natura optima dux Foundation, 600 p.

Поступила в редакиฺюю 14.11.2019

\section{Ссылка для цитирования статьи For citation}

Дедюхин С.В. 2019. Характеристика фауны и комплексов жуков-фитофагов (Coleoptera: Chrysomeloidea, Curculionoidea) шихана Куштау (Ишимбайский район Республики Башкортостан). Полевой журнал биолога. 1(4):179-192. DOI: 10.18413/2658-3453-2019-1-4-179-192

Dedyukhin S.V. 2019. Characteristics of the Fauna and Complexes of Phytophagous Beetles (Coleoptera: Chrysomeloidea, Curculionoidea) of Shihan Kushtau (Ishimbay District of the Republic of Bashkortostan). Field Biologist Journal. 1(4):179-192. DOI: 10.18413/2658-3453-2019-1-4-179-192 